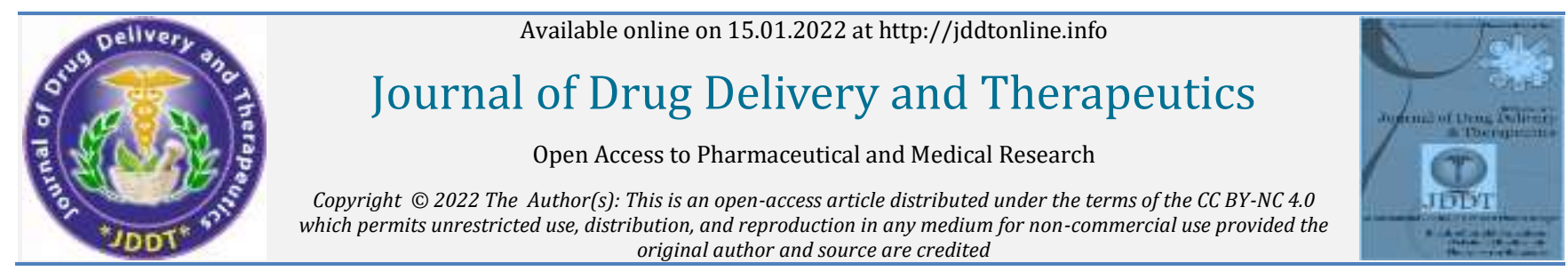

Copyright (C) 2022 The Author(s): This is an open-access article distributed under the terms of the CC BY-NC 4.0 original author and source are credited

Review Article

Open Access Full Text Article

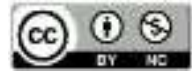

\title{
Recent Development in Floating Drug Delivery System: An Overview
}

\author{
Chaudhary Sachin*1, Dua J.S. ${ }^{1}$, Prasad D.N. ${ }^{2}$ \\ ${ }^{1}$ Department of pharmaceutics, Shivalik College of pharmacy, Naya Nangal, Punjab, India \\ ${ }^{2}$ Department of pharmaceutical chemistry, Shivalik College of pharmacy, Naya Nangal, Punjab, India
}

Article Info:

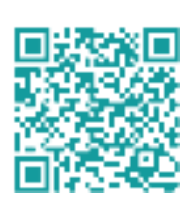

Article History:

Received 10 November 2021 Reviewed 23 December 2021 Accepted 02 January 2022

Published 15 January 2022

\section{Cite this article as:}

Chaudhary S, Dua JS, Prasad DN, Recent Development in Floating Drug Delivery System: An Overview, Journal of Drug Delivery and Therapeutics. 2022; 12(1):185-193

DOI: http://dx.doi.org/10.22270/jddt.v12i1.5171

\section{*Address for Correspondence:}

Chaudhary Sachin, Department of pharmaceutics Shivalik college of Pharmacy, Nangal, Punjab, India

\section{Abstract}

\begin{abstract}
Floating medicines work well to increase drug absorption in the stomach. On the basis of current literature, a drug for a novel drug delivery system (NDDS) is established to explicate the floating drug delivery system (FDDS). The most recent FDDS progress involves the formulation as well as physiological aspects that may affect gastric retention and formulation. This review also discusses certain ways of producing a floating system, as well as evaluation methods, characterization, and classification for the FDDS pharmaceutical dosage form. By overcoming physiological hurdles such as short stomach residence times and unexpected gastric emptying times, scientific and technological achievements have been made in the study and development of controlled-release oral drug delivery systems in recent years. So, in general, float dose systems are key technological medication delivery systems that have a stomach-retentive nature and provide a variety of options. Floating drug delivery systems (FDDS), also known as hydro dynamically balanced systems (HBS), swelling and expanding systems, polymeric bio-adhesive systems, modified-shape systems, high-density systems, and other delayed gastric emptying devices are now used to extend the GRT. The latest technological breakthroughs of FDDS, including patented delivery methods and commercialized products, are covered in this study, as well as their advantages and future possibilities for oral controlled drug administration.
\end{abstract}

Keywords- A novel drug gastrointestinal tract, types of FDDS, gastric residence time, evaluation of FDDS

\section{Introduction}

Floating systems are defined as systems with a low density, a higher buoyancy attribute, and the ability to float over gastric fluids in the stomach, allowing for longer action times. ${ }^{1}$ Oral medication administration is thought to be the most promising. A typical drug delivery method can only achieve and maintain medication concentrations within the therapeutically effective range necessary for treatment when taken numerous times per day. Drugs with short halflives and facile absorption from the gastrointestinal tract (GIT) exit the systemic circulation quickly. These drugs must be taken on a regular basis to achieve the desired results. Therapeutic activity that is suitable. The development of an oral sustained-release system formulation to get past this restriction is an attempt to progressively release the medication into the body. Maintain a healthy gastrointestinal system (GIT). For a long time, the concentration of drugs in the systemic circulation has been recognized. Gastroretentive dosage forms (GRDFs) are designed to stay in the stomach for a long time and release their active ingredients, allowing for consistent and long-term medicine distribution to the upper GI tract. The goal of any drug delivery system is to deliver a therapeutic amount of drug to the right part of the body at the right time in order to rapidly achieve and then maintain the optimal therapeutic drug concentration that triggers pharmacological activity while reducing the occurrence and severity of unwanted side effects. ${ }^{2}$

\section{Gastrointestinal retention: ${ }^{3}$}

The gastro-retention systems are designed to be held in the stomach for a lengthy period of time in order to release the active ingredients of the medications and allow medication to enter the upper gastrointestinal tract on a continuous and protracted basis. This approach has attracted a lot of interest in recent decades because of its potential to improve the oral delivery of several important drugs by increasing their oral bioavailability and/or therapeutic efficacy by allowing them to stay longer in the upper GI tract. Gastro-retentive systems can stay in the stomach for several hours, allowing drugs to spend more time there. Longer stomach retention boosts bioavailability, reduces medication waste, and boosts solubility for drugs that are less soluble at high pH. Drugs can also be delivered to the stomach and proximal small intestine using this method. ${ }^{3}$

\section{Basic gastrointestinal tract physiology: 4}

The fundus in the stomach developed as part of the proximal. The antrum is the primary place for the mixing of gestures and serves as a stomach-emptying pump through actionpushing. The body is the reservoir for ungroomed materials, and the antrum is the primary location for the mixing of gestures and functions as a stomach-emptying pump through action pushing. Gastric emptying occurs throughout both the fasting and feeding stages. Fasting: the inner digestive myoelectric migrating cycle (MMC) is divided into 
four parts and occurs during a two-to-three-hour fasting period.

\section{Stomach physiology:}

The stomach is an expanded section of the digestive tube that lies between the oesophagus and the small intestine. The stomach wall is physically comparable to the remainder of the digestive tube, with the exception of an oblique layer of smooth muscle inside the circular layer that aids in precise grinding motions. When the stomach is empty, the mucosa and submucosa are pushed up into discrete folds known as rugae. Secretary epithelial cells are illustrated in four major kinds that cover the surface of the stomach and extend down into gastric pits and glands.

In the epithelial membrane, there are four types of seceratory cells.

Mucous cells

Parietal cells

Chief cells
F-Cells

\section{Gastric emptying rate}

Gastric emptying occurs in both fasting and eating situations. However, the migratory patterns in the two states are not the same. During the fasting state, an interdigestive series of electrical events occurs, cycling through the stomach and intestine every 2 to 3 hours. According to Wilson and Washington, the interdigestive myloelectric cycle, also known as the migrating myloelectric cycle (MMC), is divided into four phases.

Phase I (basal phase): It can last anywhere from 40 to 60 minutes, with only a few contractions.

Phase II (pre-burst): It has an action potential and contractions that last 40 to 60 minutes.

Phase III (burst phase) lasts 4 to 6 minutes and contains powerful and regular contractions for a brief duration.

Phase IV: It occurs between phases III and I of two consecutive phases and lasts 0 to 5 minutes.

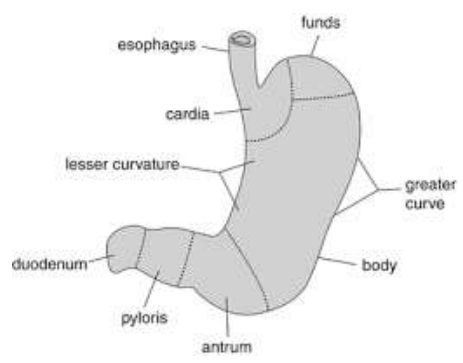

Figure 1: Basic GIT physiology.4

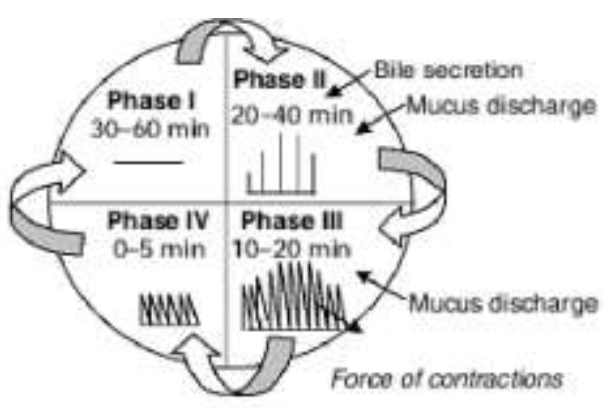

Figure 2: GIT motility pattern in fasted state. ${ }^{4}$
Gastric motility-is regulated by a complicated system of neuronal and hormonal cues. The enteric nervous system, as well as the parasympathetic nervous system (most notably the vagus nerve) and sympathetic nervous system, all contribute to neural regulation. Gastric motility is influenced by a variety of hormones; for example, both gastrin and cholecystokinin calm the proximal stomach while increasing distal stomach contractions. In the end, stomach motility patterns are most likely the product of smooth muscle cells integrating a huge variety of inhibitory and stimulatory impulses. ${ }^{4}$

\section{Approaches to gastric retention: 5}

1. Floating drug delivery systems (FDDS): These devices float over the gastric contents due to their low density.

2. Bioadhesive systems: These systems bond to the stomach mucosa, allowing for the system's localized retention.

3. Swelling and expanding systems: Swelling and expanding systems absorb water and grow in size as a result.

4. High-density systems: They settle into the folds of the stomach, allowing them to stay in the stomach for longer periods of time. 5

\section{Floating drug delivery system 6,7}

Tablets are one of the most widely used kinds of medicine on the planet. A tablet can be made from almost any medicinal molecule, and the tablet manufacturing procedure is fairly simple. Davis first described floating systems in 1968, which have a lower bulk density than gastric fluid and hence stay buoyant for a long time in the stomach. Floating systems can be effervescent or non-effervescent. In the creation of effervescent gases, excipients such as bicarbonate salts and acidic chemicals are used. When stomach acid is present, CO2 is produced.

\section{Classification of floating drug delivery system:8, 9}

\section{Single Unit Floating Dosage Systems}

a) Effervescent Systems (Gas-generating Systems)

b) Non-effervescent Systems

\section{Multiple Unit Floating Dosage Systems}

a) Non-effervescent Systems

b) Effervescent Systems (Gas-generating Systems)

C) Hollow Microspheres

d) Raft Forming Systems.

\section{Single unit floating dosage system}

Single-unit dosage forms are simpler to manufacture, but because they empty completely or partially from the stomach, they run the risk of losing their effects too soon, resulting in high variability in bioavailability and local discomfort due to a large volume of drug administered at a specific location in the gastrointestinal tract. 


\section{(a)Effervescent Systems (Gas-generating Systems)}

These are matrix forms of systems made with effervescent substances like sodium bicarbonate, citric acid, and tartaric acid, as well as swelling polymers like chitosan and methylcellulose. When $\mathrm{CO} 2$ comes into contact with acidic gastric contents, it is generated and stuck in swollen hydrocolloids, giving dosage types buoyancy.

\section{(b)Non-effervescent Systems}

Polysaccharides, hydrocolloids, and matrix-forming polymers such as polyacrylate, polycarbonate, polystyrene, and polymethacrylate are used to generate a gel-forming or swelling cellulose type in non-effervescent floating dosage forms. A straightforward strategy to completely combine the medication and the hydrocolloid-forming gel is included in the formulation method. Following oral administration, this dosage form swells in contact with stomach juices and achieves a bulk density of 1 . The air contained within the swelling matrix provides buoyancy to the dose form.

\section{(2) Multiple unit dosage form}

\section{(a) Non-effervescent Systems}

Unlike effervescent systems, there is little research on effervescent multiple-unit systems in the literature. However, few researchers have investigated the feasibility of developing an indomethacin-containing technique employing chitosan as the polymeric excipient. A model drug manufactured using the extrusion procedure is a multiple HBS unit containing indomethacin.

\section{(b) Effervescent Systems}

A calcium alginate core and a calcium alginate/PVA membrane were separated by an air compartment in a multi-unit system. In the presence of water, the PVA leaches out and increases the permeability of the membrane, preserving the integrity of the air compartment. The floating properties of the system have improved as the molecular weight and PVA content have increased. The freeze-drying procedure for making floating calcium alginate beads is also addressed. Due to the creation of calcium alginate, sodium alginate solution is dropped into an aqueous solution of calcium chloride, causing the droplet surface to quickly gel.

\section{(c) Hollow Micro spheres}

Hollow microspheres packed with pharmaceuticals were created in their outer polymer shelf using a unique approach of emulsion solvent diffusion. At 400 degrees Celsius, the drug's ethanol/dichloromethane solution and enteric acrylic polymer were poured into a thermally regulated, agitated Poly Vinyl Alcohol (PVA) solution. The gas phase is created by the evaporation of the dichloromethane created in the dispersed polymer droplet and the interior cavity in the drug polymer microsphere. For more than 12 hours, the microballoon floated continuously over the surface of a surfactant containing acidic dissolving media.

\section{The floating drug delivery system's mechanism of action is as follows: 10}

Because FDDS has a lower bulk density than gastric fluid, it can float in the stomach for longer periods of time without affecting the rate at which it empties. The medicine is gently released from the system at the desired pace while the systems are floating on the stomach material. Once the drug is released, the stomach's residual system is empty. As a result, GRT is increased, and plasma drug concentration fluctuations are better managed. A new apparatus for estimating the resulting weight has been recorded in the literature for the computation of floating force kinetics. The equipment works by continually measuring the force required to keep the submerged object afloat, which is equal to $F$ (as a function of time).

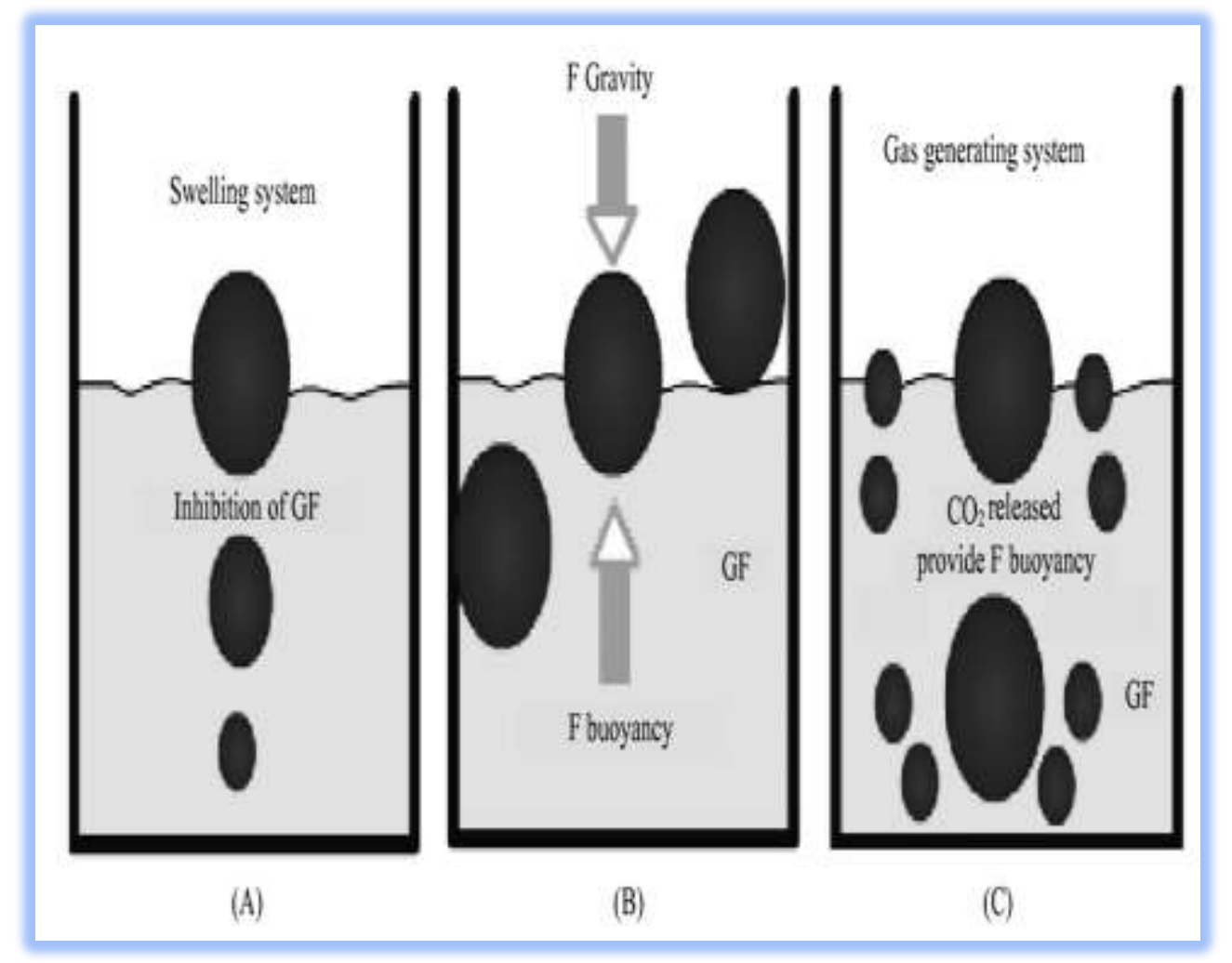

Figure 3: Mechanism of floating drug-delivery system. ${ }^{10}$ 


\section{Methods of Developing Floating Drug Delivery Systems: 11}

\section{Direct compression technique}

It entails compressing tablets directly from powder without changing the physical structure of the material. The most common carriers are dicalcium trihydrate phosphate, tricalcium phosphate, and others.

\section{Wet granulation technique}

Wet powder massaging, grinding, or drying are all involved. Instead of compacting the powders, wet granulation forms them by binding them together with an adhesive.

\section{Effervescent Technique}

The floating chamber of the medication delivery system will be filled with inert gas as a result of an effervescent reaction between organic acid (citric acid) and bicarbonate salts (CO2).

\section{Ionotropic Gelation Technique-}

The basic polymer of natural origin, anionic polysaccharide sodium alginate, was gelled with oppositely charged calcium ions (counter-ions) with the goal of creating immediate microparticles.

\section{5. solvent evaporation technique}

The capacity of a continuous phase to remove the entire amount of liquid dispersal solvent is insufficient. To obtain hardened microspheres, solvent evaporates from the dispersal surface.

\section{Spray drying technique}

Dispersing the core layer into the liquid coating content and spraying the core coating mixture into the environment to solidify the coating by rapidly evaporating the coating material.

\section{Melt solidification technique}

This method entails emulsifying the molten mass in an aqueous phase before cooling it and solidifying it. The carriers for this technique include lipids, waxes, polyethylene glycol, and others.

\section{Melt Granulation Technique-}

This is a granulation technique that uses a meltable binder to agglomerate pharmaceutical powders without the need for water or organic solvents.

Table 1: Commercially available floating Formulations. ${ }^{12}$

\begin{tabular}{|l|l|l|l|}
\hline Name of the product & Active Ingredient & Category & Name of the company \\
\hline Almagate flowcoat & Al-Mg antacid & Antacid & Ranbaxy,India \\
\hline Liquid Gaviscon & $\begin{array}{l}\text { Al hydroxide }(95 \mathrm{mg}) . \mathrm{Mg} \\
\text { carbonate }(358 \mathrm{mg})\end{array}$ & $\begin{array}{l}\text { Antacid (in reflux } \\
\text { esophagitis })\end{array}$ & Glaxo Smithkline, India \\
\hline Cytotec Bilayer capsule & Misoprostol $(100 \mathrm{mcg} / 200 \mathrm{mcg})$ & & Pharmacia, USA \\
\hline
\end{tabular}

\section{POLYMERS USED IN FLOATING DRUG DELIVERY SYSTEM}

Polymers are employed in the floating system to target medicine delivery to a specific area of the GI tract, such as the stomach. Floating medication delivery uses both synthetic and natural polymers. In the floating system, guar gum, chitosan, xanthan gum, gellan gum, sodium alginate, and other natural polymers are employed in the system. For floating drug delivery, HPMC, Eudragit, ethyl cellulose, and other synthetic polymers are utilized. 13

Polymers are of two types. ${ }^{13}$

Natural polymers

Synthetic polymers

Natural polymers- Natural gums (derived from plants) are a high-molecular-weight hydrophilic carbohydrate polymer. Organic solvents, such as hydrocarbons and ether, are generally insoluble in them. Gums are either water soluble or absorb water and swell or disperse in cold water, resulting in a viscous solution or jelly.

1. Guar gum- Guar gum is a galactomannan polysaccharide that occurs naturally. In cold water, guar gum hydrates and swells, generating viscous colloidal dispersions, or sols. This gelling feature slows the release of the medicine and makes it a versatile carrier for long-term use. There are different dosage formulations. Guar gum is used as a disintegrant and a polymer in floating medication delivery systems in the pharmaceutical industry. ${ }^{13}$

Advantages of guar gum in floating drug delivery systems:

Polymer swelling has been shown to influence the pattern and amount of medication released. During in vitro drug dissolution testing, it was discovered that guar gum formulations were essentially unaffected by stirring speed and that the dissolution profile was unaffected. ${ }^{14}$

2. Chitosan- Deacetylation of chitin produces chitosan, a natural polymer. It possesses beneficial biological features like nontoxicity, biodegradability, and biocompatibility. It's a bioadhesive polymer that's also antibacterial, making it ideal for site-specific delivery. Chitosan is a polycationic weak base having a molecular weight of 6.2-7. It becomes buoyant in nature and provides control release when added to acidic $\mathrm{pH}$ of 1.2 or neutral media. ${ }^{15}$ The rate of release can be reduced by increasing the thickness of the chitosan film $28 .{ }^{14}$ 
Table 2: List of natural polymers ${ }^{13}$

\begin{tabular}{|l|l|l|}
\hline Sr.no & Polymer & Source \\
\hline 1. & Guar gum & Endosperm of seed of cynopsis tetragonolobus \\
\hline 2. & Xanthum & Fermentation of glucose by Xanthomonas compestris \\
\hline 3. & Gellan gum & Pseudomonas elodea \\
\hline 4. & Sodium alginate & Laminaria hyperboria \\
\hline
\end{tabular}

Chitosan has the following benefits:

It produces a film that lowers the effect of gastrointestinal transit time.

For roughly 12 hours, hollow microcapsules float in gastrointestinal fluid.

The drug's release rate followed zero-order kinetics. ${ }^{14}$

3. Xanthum Gum- Xanthan gum is a high molecular weight extracellular polysaccharide made from carbohydrate fermentation in pure culture. Xanthan is a polysaccharide with a long chain and a large number of trisaccharide side chains. Gum is also resistant to common enzymes and has high solubility and stability in acidic and alkaline environments, as well as in the presence of salts.

Xanthan gum has the following benefits:

It's used to speed up or slow down the release of a medication from a formulation.

Water soluble High viscosity at low concentrations

It has the advantage of being able to release drugs with zeroorder kinetics.

4. Sodium alginate- The sodium salt of alginic acid, which is a combination of polyuronic acids made of residues of d'mannuronic acid and L-guluronic acid, is the main component of sodium alginate. The molecular weight and block structure of sodium alginate samples were studied.

\section{Typical properties:}

\section{Solubility}

In ethanol (95\%), ether, chloroform, and ethanol/water combinations with an ethanol concentration more than $30 \%$, it is practically insoluble. In addition, it is practically insoluble in other organic solvents and aqueous acidic solutions with a $\mathrm{pH}$ lower than 3 . Slow to dissolve in water, resulting in a thick colloidal solution.

\section{Viscosity (dynamic)}

Commercially available sodium alginate grades produce aqueous solutions with various viscosities. A $1 \% \mathrm{w} / \mathrm{v}$ aqueous solution with a viscosity of 20-400 mpa s (20-400 cp) at $208^{\circ} \mathrm{C}$ has a viscosity of $20-400$ mpa s $(20-400$ $\mathrm{cp})$.Concentration, $\mathrm{pH}$, temperature, and the presence of metal ions can all affect viscosity. The viscosity of a liquid reduces when the $\mathrm{pH}$ rises above ten. Coating agent, controlled-release agent, dispersing agent, dissolution enhancer, emulsifying agent, emulsion stabilizer, extendedrelease agent, film-forming agent, foaming agent, granulation aid, mucoadhesive, release modifying agent, solubilizing agent, stabilizing agent, suspending agent, sustained release agent, tablet binder, thickening agent, viscosity-increasing agent, viscosity-increasing agent. ${ }^{16}$

Synthetic polymers- Pharmaceuticals are increasingly relying on synthetic polymers. Synthetic polymers are used as binders, film coating agents, and in other applications as well. Polymers are massive macromolecules that contain a range of functional groups. Synthetic polymers can be wholly synthetic or semi-synthetic, which is a modified form of a natural polymer. The following is a list of synthetic polymers that were employed.

Hydroxymethyl cellulose

Eudragrit

Ethyl cellulose

Hydroxy methyl cellulose- Hydroxypropyl methylcellulose ethers are a type of polymer that binds, retains water, thickens, forms films, and lubricates. They are white to offwhite, odourless, and water soluble. It's a semi-synthetic, inert, viscoelastic polymer that's found in a variety of commercial products as an excipient and controlled-delivery component in oral medicaments.

\section{Ethyl cellulose-}

For more than 50 years, Ethocel (ethylcellulose polymers) has been widely employed in the pharmaceutical business. Ethylcellulose has been used in pharmaceutical formulations for a variety of purposes, including bitter active taste masking, moisture protection, stabiliser, extended release multiparticulate coating, micro-encapsulation of actives, extended release binder in inert matrix systems, solvent, and extrusion granulation.

\section{Advantages of natural polymers:}

\section{Biodegradable}

It's non-toxic and biocompatible.

The price is low.

Friendly to the environment,

There is local availability.

\section{Synthetic polymers have the following drawbacks:}

\section{Microbial contamination}

Batch-to-batch fluctuation

An uncontrolled rate of hydration

Viscosity reduction during storage.

\section{The Benefits of a Floating Drug Delivery System. ${ }^{17}$}

1. Due to the alkaline $\mathrm{pH}$ of the intestine, floating drugs of all kinds, such as capsules or tablets, will linger in the fluid for a long time.

2. The dissolving of the medicine in the stomach fluid occurs when prolonged release floating dosage forms, such as tablets or capsules, are administered. They dissolve in gastric fluid and are available for absorption in the small intestine after the stomach contents have been emptied. As a result, even at the alkaline $\mathrm{pH}$ of the intestine, it is envisaged 
that a medication will be fully absorbed from floating dosage forms if it remains in the solution state.

3. The gastro-retentive system is beneficial for medications that are absorbed through the stomach. e.g. Ferrous salts and antacids.

4. Advantageous for medications that have a local effect in the stomach, such as antacids.

5. The FDDS formulation is effective in intestinal movement and diarrhoea to keep the medicine in a floating state in the stomach, allowing for a greater reaction.

6. FDDS promotes patient compliance by reducing dosage frequency.

7. Treatment for gastrointestinal problems such as gastroesophageal reflux.

8. Despite the first-pass effect, bioavailability is not affected since the plasma drug concentration is not affected.

9. Because aspirin and other similar drugs are acidic and cause stomach irritation, HBS/FDDS formulations may be useful for their administration.

10. Benefits from medications that are absorbed by the stomach, such as ferrous salts and antacids.

11. The medicine is delivered to a specific location.

\section{Disadvantages of the floating drug delivery system:18}

1. Drugs that are unstable in the stomach's acidic environment are not ideal candidates for incorporation into the system. The presence of food is frequently required in these systems to prolong stomach emptying.

2. It is not recommended for medications that have an issue with GIT stability or solubility.

3. Medications that have a substantial absorption rate and those that have first-pass effect only desirable candidates are found throughout the gastrointestinal tract.

4. The dosage form's tendency to float is determined by its hydration condition. Water that comes and goes from administration is beneficial in keeping these tablets afloat. 18

5. Many factors influence stomach retention, including gastric motility, $\mathrm{pH}$, and the presence of food. Because these variables are never consistent, buoyancy cannot be anticipated.

6. Drugs that irritate or damage the stomach mucosa should not be incorporated into floating drug delivery devices.

7. Due to its all-or-none-emptying method, there is a lot of variation in gastric emptying time.

8. In supine subjects, gastric emptying of floating forms can happen at any time and is strongly dependent on the diameter and size. As a result, floating forms should not be given to patients right before bedtime.

9. Because of solubility and stability concerns in the GIT, drugs that induce irritation to the gastric mucosa are not ideal for this system.

\section{Formulation excipients used in floating drug delivery systems: 19}

\section{Polymers}

Eudragit S100, Eudragit RL, Propylene foam, Eudragit RS, ethyl cellulose, poly methyl methacrylate, Methocel K4M,
Polyethylene oxide, Cyclodextrin Polyethylene glycol, polycarbonate, PVA, polycarbonate, sodium alginate, sodium alginate, sodium alginate, HPC-L, CP 934P, HPC, Eudragit S, HPMC, Metolose S.M. 100, PVP, HPC-H, HPC-M, HPMC K15, Polyox, HPMC K4, Acrylic polymer, E4 M, and Carbopol are all HPC-L, CP 934P, HPC, Eudragit S, HPMC, Metolose S.M. 100, PVP, HPC-H, HPC-

\section{Inert fatty materials (5-75\%)}

Edible inert fatty materials with a specific gravity of less than one can be employed to reduce the hydrophilic property of the formulation and therefore boost buoyancy. Beeswax, fatty acids, long-chain fatty alcohols, and gelucires $39 / 01$ and $43 / 01$ are only a few examples.

1. Sodium bicarbonate, citric acid, tartaric acid, Di-SGC (DiSodium Glycine Carbonate, CG) are effervescent agents (Citroglycine).

\section{Accelerators of the release rate $(5 \%-60 \%)$ :}

Lactose and mannitol, for example,

3. Releasing rate retardants (5\% to $60 \%$ ):

Examples include dicalciumphosphate, talc, and magnesium stearate.

4. Agents that increase buoyancy by up to $80 \%$ :

For example, ethyl cellulose

5. Polypropylene foam powder is a low-density substance (AccurelMP 1000).

\section{Factors affecting the floating drug delivery system: 20, 21, 22, 23, 24}

1. Density: The density of a dose form determines its buoyancy and, as a result, its floating efficiency. The dose form's density should be lower than the stomachic contents $(1.004 \mathrm{gm} / \mathrm{ml})$

2. Shape of dosage form: Tetrahedron and ring-shaped devices have a higher floating potential than other shapes. They have a 90-98 percent higher rate of 24-hour retention. ${ }^{20}$

3. Fed or unfed state: GI motility is characterized by periods of robust motor activity, or migrating myoelectric complexes (MMC), which occur every 1.5 to 2 hours under abstinence settings. ${ }^{21}$

4. Formulation of a single or multiple units: Multiple unit formulations permit a larger margin of safety against dosage form failure compared with single unit dosage forms.

5. Nature of meal: Feeding indigestible polymers or fatty acid salts to the stomach can cause it to shift its motility pattern to a fed state, slowing gastric emptying and prolonging medication release.

6. Calorie content: A high-protein, high-fat meal can extend floating time by $4-10$ hours.

7. Frequency of feed: Because of the low frequency of migratory myoelectric complex, the GRT will increase by over 40 minutes when successive meals are provided instead of a single meal (MMC). ${ }^{22}$

8. Posture: The GRT will differ between the patient's supine and upright ambulant stages. In the case of the floating systems, it was rumored that when individuals were kept in an upright ambulant position, the dosage type stayed consistent on stomachic content, as opposed to when they were in a supine position. As a result, the floating drug 
delivery system inside the upright position of the patients is safeguarded against post-prandial evacuation. ${ }^{23}$

9. Age: Elderly people, those over the age of 60 , have a much longer floating time.

10. Biological factor: Floating might vary depending on a person's health or physiological status. Diabetes and Crohn's illness, for example, affect floating time. ${ }^{24}$

11. Concomitant drug administration: Floating time is affected by anticholinergics like atropine, opiates like codeine, and prokinetic drugs like metoclopramide and cisapride. ${ }^{25}$

\section{Evaluation of the Floating Drug Delivery \\ System: 26, 27, 28, 29, 30, 31, 32, 33}

1. Bulk density: It's the proportion of a powder's total mass (m) to its bulk volume (Vo).

\section{$\mathrm{Db}=\mathrm{m} / \mathrm{Vo}$}

2. Tapped density: It's the ratio of powder total mass (m) to powder tapped volume (Vi).

$$
\mathrm{Dt}=\mathbf{m} / \mathbf{V i}
$$

3. Compressibility index: The bulk density (o) and tapped density $(\mathrm{t})$ of powder, as well as the rate at which it packs down, can be used to determine the flowability of powder. The compressibility index is obtained using

$$
=\frac{\rho t-\rho 0}{\rho t} \times 100
$$

Where,

$\mathbf{\rho}=$ Bulk density $\mathrm{g} / \mathrm{ml}$,

$\boldsymbol{\rho} \mathbf{t}=$ Tapped density $\mathrm{g} / \mathrm{ml}$.

4. Hausner's Ratio: It is calculated by taking the Tapped density and dividing it by the Bulk density using the formula below.

Hausner's Ratio= Tapped density / Bulk density

Table 3: Specification for Carr's index and Hausner's ratio. $^{29}$

\begin{tabular}{|l|l|c|l|}
\hline SI.No. & Flow ability & $\begin{array}{l}\text { Carr's index } \\
(\%)\end{array}$ & $\begin{array}{l}\text { Hausner's } \\
\text { ratio }\end{array}$ \\
\hline 1. & Excellent & $0-10$ & $1.00-1.11$ \\
\hline 2. & Good & $10-15$ & $1.12-1.18$ \\
\hline 3. & Fair & $16-20$ & $1.19-1.25$ \\
\hline 4. & possible & $21-25$ & $1.26-1.34$ \\
\hline 6. & poor & $26-31$ & $1.34-1.45$ \\
\hline
\end{tabular}

Table 4: The relationship between Angle of repose and powder flow. 30

\begin{tabular}{|c|l|}
\hline Angle of repose & Powder flow \\
\hline$<25$ & excellent \\
\hline $25-30$ & good \\
\hline $30-40$ & passable \\
\hline$>40$ & Very poor \\
\hline
\end{tabular}

5. Angle of repose: In this experiment, a funnel is filled with an accurately weighed mixture of powder, granules, and microparticles. The funnel's tip can be adjusted such that it just touches the apex of the blended heap. The mixtures are allowed to flow freely through the funnel on a horizontal surface. The diameter of the accelerated mass (powder, granules, or microparticles) will be measured, and the angle of repose will be calculated using the equation below.

$\operatorname{Tan} \theta=(h / r)$

$\theta=\tan -1(h / r)$

$\theta=$ angle of repose

$\mathrm{h}=$ height of the heap

$r=$ radius of the heap

6. Tablet dimensions: A calibrated Vernier Caliper was used to measure thickness and diameter. Three tablets of each formulation were chosen at random and measured separately for thickness.

7. Hardness: Hardness indicates a tablet's capacity to withstand mechanical shocks while in use. A Monsanto hardness tester was used to assess the tablets' hardness. It was measured in kilogrammes per square meter. Three tablets were chosen at random and their hardness was determined.

8. Friability test: The Roche Friabilator was used to assess the friability of tablets. It was given as a percentage (percent). To begin with, ten tablets were weighed (W) and placed in the friabilator. The friabilator was spun at $25 \mathrm{rpm}$ for 4 minutes, or turned up to 100 times. The tablets were weighed once again (Wo). A formula was used to compute the percent friability.

$$
\% \mathrm{~F}=100(1-\mathrm{Wo} / \mathrm{W})
$$

Tablets with a percentage friability of less than $1 \%$ were deemed desirable.

9. Table density: For floating tablets, tablet density was an excellent criterion. When the tablet's density is substantially lower than that of gastric juice, it can float most effectively (1.04). The density was calculated using the following formula:

$\mathbf{V}=\pi \mathbf{r} \mathbf{h}$

$\mathbf{d}=\mathbf{m} / \mathbf{v}$

Where,

$\mathrm{v}=$ volume of tablet $(\mathrm{cc})$

$\mathrm{r}=$ radius of tablet $(\mathrm{cm})$

$\mathrm{h}=$ crown thickness of tablet $(\mathrm{g} / \mathrm{cc})$

$\mathrm{m}=$ mass of tablet

10. Weight variation experiment: To test for weight variation, ten pills were chosen at random from each batch and weighed individually. The United States Pharmacopoeia allows for some variation in tablet weight.

11. Determination of buoyancy lag time: The buoyancy lag is the time it takes for the tablet to rise to the surface and float. The buoyancy of pills was investigated in $900 \mathrm{ml}$ of artificial stomach fluid at $370.5 \mathrm{oC}$. The buoyancy lag time was measured with a stop watch, and the entire floating time was visually observed.

12. Floating time: throughout the investigation, float time was monitored using a USP dissolving apparatus-II at 50 rpm with $900 \mathrm{ml}$ of $0.1 \mathrm{~N} \mathrm{HCl}$ and a temperature of $370.5 \mathrm{oC}$. 
Visual observation is used to determine the length of time the tablet floats within the dissolution media (including floating lag time, which is the time it takes for the tablet to rise to the surface).

13. Swelling index: The floating sustained release layer tablets were subjected to a swelling test. The tablets were placed in a USP dissolution apparatus II containing $900 \mathrm{ml}$ of $0.1 \mathrm{~N} \mathrm{HCl}$ and allowed to expand to a constant weight while being kept at 372 oC. The tablets were removed, wiped with filter paper, and the weight changes were calculated. The experiments were carried out three times. The method was then used to calculate the degree of swelling (the swelling index).

$$
\text { Swelling index }=\frac{\left(\mathrm{W}_{\mathrm{g}}-\mathrm{W}_{\mathrm{o}}\right)}{\mathrm{W}_{\mathrm{o}}} \times 100
$$

Where,

Wo is the initial weight of tablet.

Wg is the weight of tablet at equilibrium swelling in the medium.

14. Drug content: Five tablets from a batch were picked at random, weighed, and ground in a mortar. In a standard flask, a properly weighed quantity of powdered tablets equivalent to $100 \mathrm{mg}$ was placed and filled to the mark with $0.1 \mathrm{~N} \mathrm{HCL}$; the solution was then filtered through a $0.45 \mathrm{um}$ membrane paper. The spectrophotometric method was used to conduct the analysis.

\section{Surface topography-}

The surface topography and structures were determined using a scanning electron microscope (SEM, JEOL JSM-6701 F, Japan) with a 10 k.v acceleration voltage, a contact angle meter, atomic force microscopy (AFM), and a contact profiliometer (Ichikawam et al.,1991).

\section{In-vitro dissolution studies:}

The USP dissolving testing device II was used to measure the release rate of floating tablets (Paddle type). The dissolution test was performed at $37^{\circ} \mathrm{C}$ with $900 \mathrm{ml}$ of $0.1 \mathrm{~N}$ HCL. Every hour for 12 hours, a sample $(5 \mathrm{ml})$ of the solution was obtained from the dissolving equipment, and the samples were replaced with fresh dissolution media. The absorbance of these solutions was measured after the samples were passed through Whatman's filter paper.

\section{Application of the Floating Drug Delivery System: 34}

Enhanced bioavailability: When riboflavin CR-GRDF is given instead of non-GRDF CR polymeric formulations, the bioavailability of riboflavin CR-GRDF is significantly higher.

Sustained delivery of drugs: The GIT had issues with oral CR formulations, such as gastric residence time. HBS systems that can stay in the stomach for an extended period of time, have a bulk density of less than one, and float on the gastric contents are usually able to overcome these issues.

System of site-specific drug delivery: The drug is delivered to the stomach in a regulated, progressive manner, resulting in optimal local therapeutic rates and less systemic exposure. Extended gastric availability from a site-driven medication delivery device can reduce dose frequency. For instance, furosemide and riboflavin.

Improvement of absorption: By enhancing their absorption, drugs with low bioavailability due to siteISSN: 2250-1177 specific absorption from the upper part of the GIT could be created as floating drug delivery device.

Minimized adverse reactions in the colon: In HBS, the medicine is retained in the stomach, reducing the amount of drug that enters the colon. As a result, unwanted drug activity in the colon can be prevented.

Reduced fluctuations at drug concentration: In comparison to other types of immediate release dosage forms, continuous input of the drug after CR-GRDF delivery results in a narrower range of blood drug concentrations.

\section{Conclusion}

A current endeavor is the development of an effective gastro-retentive dosage form for stomach-specific medication delivery. As a result, numerous ways were attempted to achieve the desired gastro retention, with the floating medication delivery system emerging as the most promising.

These systems allow for greater absorption of medications absorbed from the top section of the stomach, resulting in increased bioavailability and regulated distribution of numerous pharmaceuticals, providing new and important treatment alternatives. As a result, dosing is less frequent, and the treatment is more effective. Such a system is more reliable since it has superior stability and medication release than other traditional dose forms. Medication absorption in the GI tract is a highly variable system, and prolonged GI retention of the dose form extends the time it takes for the drug to be absorbed. The floating drug delivery device is certain to be a gastric retention approach. Despite the fact that there is a large range of Many firms are concentrating on commercializing this strategy, despite the obstacles that must be worked out in order to get extended GI retention. It is clear from the wide range of industrial products and patents issued in this industry.

\section{References:}

1. Aditya S, Vishkha C, Tahir N, Neelesh M, Namrata R, Vyas I. Formulation and Evaluation of Floating Tablet of Tropisetron Sharma, J Drug Deliv Ther. 2019; 9(2-A):44-6.

2. Pattanaya D, Mondal K, Hooain M, Das S, Ali M. A review on floating drug delivery systems in present scenario, Int J Pharm Res Health Sci. 2018; 6(5):2755-62.

3. Yadav S, Yadav S, Mishra A, Kumar A and Kushwaha SS, Floating Drug Delivery System an Aid to Enhance Dissolution Profile of Gastric, Journal of Drug Delivery \& Therapeutics. 2021; 11(6):286-296 https://doi.org/10.22270/jddt.v11i6.5153

4. Sopyan, I., \& Wahyuningrum, R. A review: Floating drug delivery system as a tool to improve dissolution rate in gastric, International Journal of Applied Pharmaceutics, 2020:51-54. https://doi.org/10.22159/ijap.2020v12i4.38415

5.Niharika M.G, Krishnamoorthy K, Akaala M. overview on floating drug delivery system, International journal of applied pharmaceutics.2018; 10(6):65-71 https://doi.org/10.22159/ijap.2018v10i6.28274

6. Khairnar VS, Patil ST, Pawar SP. Effervescent Drug Delivery System, International Journal of Pharma and Chemical Research. 2017; 3(2):260-266.

7. Wang L, Liu X. Sustained Release Technology and Its Application in Environmental Remediation: A Review, Environmental Research and Public Health. 2019; 16(12):2153. https://doi.org/10.3390/ijerph16122153

8. Datir SK, Patil PB, Saudagar RB. Floating type drug delivery system: a review, J Drug Deliv Ther. 2019; 9(2):428-32. https://doi.org/10.22270/jddt.v9i2.2492 
9. Patil P, Baviskar P, Saudagar RB. Floating Drug Delivery System: A comprehensive review, J Drug Deliv Ther. 2019; 9(3-s):839-46. https://doi.org/10.22270/jddt.v9i4-s.3384

10.Farooq SM, Sunaina S, Rao M, Venkatesh P, Hepcykalarani D, Preama R. Floating Drug Delivery Systems: An updated Review, Asian Journal of Pharmaceutical Research. 2020 Mar 9; 10(1):39-47. https://doi.org/10.5958/22315691.2020.00009.X

11. Tripathi J, Thapa P, Maharjan R and Jeong SH. Current State and Future Perspectives on Gastroretentive Drug Delivery Systems, Pharmaceutics. 2019; 11(4):122.

https://doi.org/10.3390/pharmaceutics11040193

12. Kamalakkannan V, Pyratchikody A, Viswanadhan VP,"Enhancement of Drugs bioavailability by Floating Drug Delivery System-A Review."Int. J. Drug Delivery.2011; 3(4): 558-570.

13. Zubedi S.S, Mohammed S . floating tablet and its polymers, Journal of Drug Delivery \& Therapeutics. 2018; 8(5-s):16-24 https://doi.org/10.22270/jddt.v8i5-s.1928

14. Kumar G. Natural Polymers in the Development of Floating Drug Delivery Systems: A Review, Int. J. Pharm. Life Sci, 2013; 2(4):165-178. https://doi.org/10.3329/ijpls.v2i4.17116

15. Singh A, kumar. Role of Natural Polymers Used In Floating Drug Delivery System Floating Drug Delivery System. J. Pharm. Sci. Innov, June. 2012; 1:11-15.

16. Milanovic J., Manojlovic V., Levic S., Rajic N., Nedovic V. \& Bugarski B. Microencapsulation of Flavors in Carnauba Wax. Sensors, 2010; 10:901-912. https://doi.org/10.3390/s100100901

17. Thakur S, Ramaya k, Saha D K, Raj k. Floating Drug Delivery System,Journal of Drug Delivery \&Therapeutics. 2021; 11(3s):125-130 https://doi.org/10.22270/jddt.v11i3-S.4828

18. Roshani K, Panda P, Vishwakarma DK, Verma NK. A brief review on bilayer floating A brief review on bilayer floating tablet, International Journal of Advances in Pharmaceutics. 2017; 6(3):70-78.

19. Rathod H, Patel V and Modasia M. Floating drug delivery system: Innovative Approach of Gastroretention, Int J Pharm Sciences Review and Research. 2010; 4(3):183-191.

20. Kaushik AY, Tiwari A K and Gaur A. Role of Excipients and polymeric advancements in preparation of floating drug delivery systems, Int J Pharm Investig. 2015; 5(1):1-12. https://doi.org/10.4103/2230-973X.147219

21. Pakhale NV, Gondkar SB, Saudagar RB, Effervescent Floating Drug Delivery System: A Review, Journal of Drug Delivery and Therapeutics. 2019; 9(3-s):836-838.

https://doi.org/10.22270/jddt.v9i4-A.3490
22. Padhan et al. Floating Oral In-situ Gel, A Comprehensive Approach of Gastroretentive Drug Delivery System: A Review, IJPSR. 2019; 10(9):4026-4039.

23. Kumari B. Recent Development in Floating Drug Delivery System: A Review, Asian Journal of Pharmacy and Pharmacology. 2018; 4(2):131-139. https://doi.org/10.31024/ajpp.2018.4.2.6

24. Jaimini R, Gupta MK, Sharma V. A Review on Formulation and Evaluation of Gastroretentive Floating Tablet of Nifedipin, Journal of Drug Delivery and Therapeutics. 2019 Jul 15, 9(4):651-6.

25. Nur A.0, Zhang J.S. Captopril floating and/or bioadhesive tablets: design and release kinetics.Drug Dev Ind Pharm. 2000; 26:965969. https://doi.org/10.1081/DDC-100101323

26. Sopyan I, Sriwidodo, Wahyuningrum R, Norisca Aliza P. A review: Floating drug delivery system as a tool to improve dissolution rate in gastric, Int J Appl Pharm. 2020; 12(4):51-4. https://doi.org/10.22159/ijap.2020v12i4.38415

27. Sharma N, Agarwal D, Gupta MK and Khinchi MP. A Comprehensive Review on Floating Drug Delivery System, Int J Res Pharm Biomed Sci. 2011; 2(2):428-41. https://doi.org/10.7439/ijbr.v2i6.118

28. Gadhve MV, Lende LK, Tajane TS and Gaikwad DD. Formulation and Development of Bilayer Floating Tablet of Nifedipine using surface solid dispersion technique, Int J Adv Pharm. 2016; 5(5):117

29.Reddy R.S, Ramachandra C.T, Hiregoudar S, Nidoni U.K, Kammar $\mathrm{M}$, and Ram J. influence of processing conditions on functional and reconstitution properties of milk powder made from Osmanabadi goat milk by spray drying, Small Ruminant Res. 2014; 119:130-137.

https://doi.org/10.1016/j.smallrumres.2014.01.013

30. Chaudhary A, Renthlei L, Dewan M, Ahmed R, Barakoti H, and Dey B.k. floating drug delivery system: an outlook, Journal of applied pharmaceutical research. 2019; 7(3):1-8. https://doi.org/10.18231/j.joapr.2019.003

31. Moursy N.M, Afifi N.N, Ghorab D.M, ElSaharty Y. Formulation and evaluation of sustained release floating capsules of Nicardipine hydrochloride, Pharmazie. 2003; 58:38-43.

32. Pakhale NV, Gondkar SB, Saudagar RB. Effervescent Floating Drug Delivery System: A Review, Journal of Drug Delivery and Therapeutics. 2019; 9(3-s):836-838. https://doi.org/10.22270/jddt.v9i4-A.3490

33. Sonar G. S. Bioadhesive-floating matrix tablet of salbutamol sulphate using response surface methodology: optimization and in vitro evaluation, J Pharm Res. 2009; 2(5):908-914.

34. Sharma V, Rathore D, Kumar A. Floating drug delivery system: a review, International Journal of Medical and Biomedical Studies. 2020; 4(8):23-30 https://doi.org/10.32553/ijmbs.v4i8.1333 